\title{
Is Vision Zero important for promoting health?
}

Vision Zero for road safety was an innovative road safety policy first adopted by the Swedish government in 1997 (Tingvall, 1998). The long term policy objective is that no one shall be killed or seriously injured in traffic. Central to the approach is that the responsibility for transport safety is shared between the users (the public) and system designers such as the local and national government, the automotive industry, and infrastructure owners (Fahlquist, 2006). To support this long term vision, interim casualty reduction targets are set for the number of people killed and seriously injured and are the basis of managing performance towards achieving the targets.

Of course such policies aim to protect people from injury - a negative health outcome - but there is renewed interest in Vision Zero as a way to not only protect life but promote health and wellbeing - a clear recognition of the interdependence or nexus between transport and health (http://www.government.se/4a800b/contentassets/b38a99b2571e4116b81d6a5eb2aea7 1e/trafiksakerhet_160927_webny.pdf ). Whilst most countries (especially the Northern European high performers) who have adopted a targeted approach have seen reductions in casualties, recent trends show a stalling in progress and a far slower rate of casualty reduction for cyclists and pedestrians compared with car occupants (ITF 2017). If we do not increase efforts to improve safety for pedestrians and cyclists then we may not be able to mobilise these modes to achieve other societal goals aimed at health and wellbeing (Cairns et al, 2014). Many countries have ambitions to encourage mode shift from motorised individual transport to walking and cycling to address societal goals such as reducing air pollution and global climate change caused by transport, to reduce respiratory diseases, and increase levels of physical activity to reduce the epidemic of obesity and consequent burden of disease.

Furthermore, these policy objectives are unlikely to be reached unless the dangers posed by motorised private transport are reduced. Perceived safety is often cited as the main deterrent to the adoption of more sustainable modes of travelling and there is a growing movement to adopt a road danger reduction approach (Carver et al; 2010; Tight and Hine 2017; Tight et al, 1998)

In the Vision Zero approach there is a clear responsibility for stakeholders responsible for the design and implementation of the transport system to ensure that when people make mistakes the system can accommodate them and manage the impact energy levels to reduce the likelihood of death or serious injury. This is called the safe system approach and the key pillars of this are creating safe speeds, safe streets, safe vehicles, safe users and if a collision occurs to enable a quick response to the crash to administer medical treatment and care.

Arguably, in order for transport to deliver health we need a nexus between transport and health practitioners and experts who have a responsibility for shaping the system. Transport for London are currently consulting about how best to connect the health and transport agenda. The recently published Mayor's 2018 Transport Strategy proposes to adopt a Vision Zero approach within a healthy streets, healthy people policy: 'working towards the elimination of road traffic deaths and serious injuries by reducing the dominance of motor vehicles on London's streets - will be central to the overall success of the Healthy Streets Approach.' https://tfl.gov.uk/corporate/about-tfl/how-we-work/planning-for-the-future/themayors-transport-strategy 
The interplay between transport interventions and their impact on health will provide new challenges for policy evaluation. Good quality information at micro and macro scale will be required to explore the public health benefit of a 'healthy streets' policy incorporating Vision Zero. Ubiquitous mobile sensing using smart phones or wearables can be used to monitor behaviour and physical activity, combined with collect self-reported travel behaviour and physical activity levels before as well as after a healthy streets intervention (Reddy et al, 2010) - although of course it is still a challenge to ensure mobile phones are not a cause of distraction for road users, particularly drivers (Sullman et al. 2018, Editor's Choice). Such technologies will allow calculation of individual changes over time and can be linked with the intervention and other contextual data such as the characteristics of the traffic and the occurrence of collisions. Triangulating these data sources is a non-trivial task and will require new skills among the workforce.

We also need to reflect on competing policy objectives which may pose a significant barrier to implementing Vision Zero and creating heathy streets for healthy people. Arguably the success of reducing car occupant casualties is because of the automotive industry's adoption of greater protection and assistive and autonomous systems to improve safety for car occupants. However, speed has not been addressed by automotive manufacturers and governments are reluctant to regulate because the dominant paradigm is that travelling quickly promotes economic growth. Unless these two factors - speed and economic growth are decoupled there may be little hope of making further gains in creating healthier streets. The costs of unhealthy streets also need to be included in the economic equation (Andersen et al. 2018; Ohlin et al. 2018). The future introduction of connected and autonomous vehicles may provide an opportunity for system designers (government, automotive manufacturers, digital industries) to take responsibility for safer speeds. Automation software will depend on creating a digital twin of the regulated environment which means (in theory) that no vehicle will be allowed to go above the posted speed limit. This future scenario may well help reduce the perceived and actual danger of motorised transport for pedestrians and cyclists - perhaps then active travel will flourish, though autonomous vehicles may have both positive and negative effects on health (Crayton and Meier 2017). However, it is unlikely that we will ever be completely free of human errors in the design and operation of such a system and the spectre of cyber security is ever present (Cohen et al, 2017).

\section{References}

Andersen, L.B., Riiser, A., Rutter, H., Goenka, S., Nordengen, S., Solbraa, A.K., 2018. Trends in cycling and cycle related injuries and a calculation of prevented morbidity and mortality. Journal of Transport \& Health Vol 9, ELSEVIER TO INSERT PAGE NUMBERS https://doi.org/10.1016/j.jth.2018.02.009.

Cairns, J., Warren, J., Garthwaite K., Greig, G., Bambra, C., 2015. Go slow: an umbrella review of the effects of $20 \mathrm{mph}$ zones and limits on health and health inequalities. Journal of Public Health, Volume 37, Issue 3, 1 2015, Pages 515-520, https://doi.org/10.1093/pubmed/fdu067 
Carver, A., Timperio, A., Hesketh, K., Crawford, D., 2010. Are children and adolescents less active if parents restrict their physical activity and active transport due to perceived risk?

Social Science \& Medicine, Volume 70, Issue 11, 2010, Pages 1799-1805

Cohen, T., Jones, P., \& Cavoli, C. M., 2017. Social and behavioural questions associated with automated vehicles. London, UK: Department for Transport.

Crayton, T.J., Meier, B.M., 2017. Autonomous vehicles: Developing a public health research agenda to frame the future of transportation policy. Journal of Transport \& Health 6, 245252.

International Transport Federation. 2017, Road Safety Annual Report 2017, OECD Publishing, Paris. http://dx.doi.org/10.1787/irtad-2017-en

Ohlin, M., Kjeldgård, L., Elrud, R., Stigson, H., Alexanderson, K., Friberg, E., 2018. Duration of sickness absence following a bicycle crash, by injury type and injured body region: A nationwide register-based study. Journal of Transport \& Health Vol 9, ELSEVIER TO INSERT PAGE NUMBERS https://doi.org/10.1016/j.jth.2018.01.011.

Reddy, S., Mun, M., Burke, J., Estrin, D., Hansen, M., Srivastava, M. 2010. Using mobile phones to determine transportation modes. ACM Trans. Sensor Netw. 6, 2, Article 13 (February 2010), 27 pages. DOI $=10.1145 / 1689239.1689243$

http://doi.acm.org/10.1145/1689239.1689243

Sullman, M.J.M., Przepiorka, A.M., Prat, F., Blachnio, A.P., 2018. The role of beliefs in the use of hands-free and handheld mobile phones while driving. Journal of Transport \& Health Vol 9, ELSEVIER TO INSERT PAGE NUMBERS https://doi.org/10.1016/j.jth.2018.04.001.

Julian Hine, J., and Tight, M., 2017. Road Danger Reduction: a research challenge. Editorial Journal of Transport \& Health, Volume 7, Part A, December 2017, Pages 1-2

Tight, M., Page, M., Wolinski, A., Dixey, R., 1998. Casualty reduction or danger reduction: conflicting approaches or means to achieve the same ends? Transport Policy. Volume 5, Issue 3, 1998, Pages 185-192.

Tingvall, C., 1998. The Swedish 'Vision Zero' and how parliamentary approval was obtained. Keynote address at Researchers Conference, NZ, and 'Road Safety Summit', Canberra 1998, pp. 57-61. 